\title{
COMPUTER VISION SYNDROME: REVIEW AND METHODS FOR ASSESSMENT
}

\author{
Panayot N. Nikolov \\ Department of Hygiene and Epidemiology, Faculty of Public Health, Medical \\ University Varna, Bulgaria.
}

\begin{abstract}
:
Computer vision syndrome (CVS) is a combination of eye and vision problems associated with the use of digital devices. CVS affects the eyesight, visual comfort and occupational productivity of workers due to the different symptoms computer users and staff experience: ocular discomfort, headache, dry eye, blurred vision etc.

Aim of the study: To assess the symptoms of CVS in a software company in Varna by subjective and objective tests and prescribe measures for prevention.

Materials and methods: 40 participants - 31 men and 9 women were distributed with a valid questionnaire regarding common symptoms of CVS. The group was tested with the Schirmer test to measure the tear film quantity. Participants have passed a medical exam by an ophthalmologist before the study.

\section{Results:}

- 11 or $27,5 \%$ of the participants in the questionnaire have reached score $\geq 6$ - have CVS

- 10 or $25 \%$ of the participants in the Schirmer test have reached results $<5 \mathrm{~mm}$. in the tear strip

- The gender distribution shows 3 women $(33.33 \%)$ and $8(25.8 \%)$ of men have CVS by questionnaire study and $3(33.33 \%)$ of women and $7(22.6 \%)$ of men based on Schirmer test have dry eye as asymptom of CVS.

Conclusion: The results of the study predispose to further evaluation and tracking of the symptoms of CVS among this occupational group. All of the participants are aware of Ordinance No. 7 related to health and safety work conditions with VDT's and received information regarding the physiological work-rest regime. Occupational risk of CVS can be reduced with early diagnose, assessment and prevention of the symptoms.
\end{abstract}

Keywords: CVS, occupation, digital device, assessment, digital eyestrain,

\section{INTRODUCTION:}

In the modern digital age, the use of electronic devices is crucial for almost all occupations and parts of the industry. The important economic role of the IT industry on both developed and developing countries leads to increased need for health prophylaxis among the staff for better working ability and reduction of occupational-related pathology. Computer vision syndrome represents combination of eye and vision problems associated with the use of computers and all types of digital devices. The most common reported symptoms of CVS are ocular discomfort, headache, asthenopia, dry eye, blurred vision.Studies show that 64 to $90 \%$ of computer users report these symptoms after prolonged use [1]. A survey of 419 computer users in India showed that about $46.3 \%$ of the users experienced multiple symptoms either during or after computer work: itching in the eyes, pain,sensitivity, redness, tears in excess, dryness, blurred vision and discoloration of objects [2]. CVS symptoms are strongly influenced by the visual demand and duration of the task [3]. Use of blue blocking filters has an unproven impact on reducing the symptoms of CVS [4]. People who spent more than 4 hours working at a computer display experience a greater incidence of the symptoms [5]. A ten years study of visual fatigue reports that it is related to the time of use by VDT workers [5]. A comparison between symptoms of CVS reported that their severity and score were more increased after visual tasks on a computer than those done on hard copy fixation [6]. Prevention strategies like providing an ergonomic work environment and practice through proper education and implementation of ergonomic workplace policies are the main elements of the management of CVS [7].

\section{MATERIAL AND METHODS:}

During a periodical medical examination of workers in IT company, a group of 40 participants-31 men and 9 women was studied. The average age of the participants is $28 \pm 0,5$ years. The studied group of employees was divided according to their work experience to less or more than 5 years. All of the participants use more than 4 hours per day of digital devices.

Methods: The studied group was distributed with a valid questionnaire regarding common symptoms of CVS. The questionnaire assesses the frequency and intensity of 16 symptoms using a single rating scale [8]. To the group was conducted a Schirmer tear strip test to measure the tear film. All of the tested participants have undergone medical examination by an ophthalmologist before the start of the study-all of them are declared to be free of any diseases that contraindicate study with the questionnaire [8]. 


\section{RESULTS:}

- 11 or $27,5 \%$ of the participants in the questionnaire have reached score $\geq 6$ - considered to suffer CVS [Fig1]

- 10 or $25 \%$ of the participants in the Schirmer test have reached results lower than $5 \mathrm{~mm}$. in the tear stripconsidered to have a dry eye (Fig. 1)

Fig. 1. Comparison of the results of symptoms

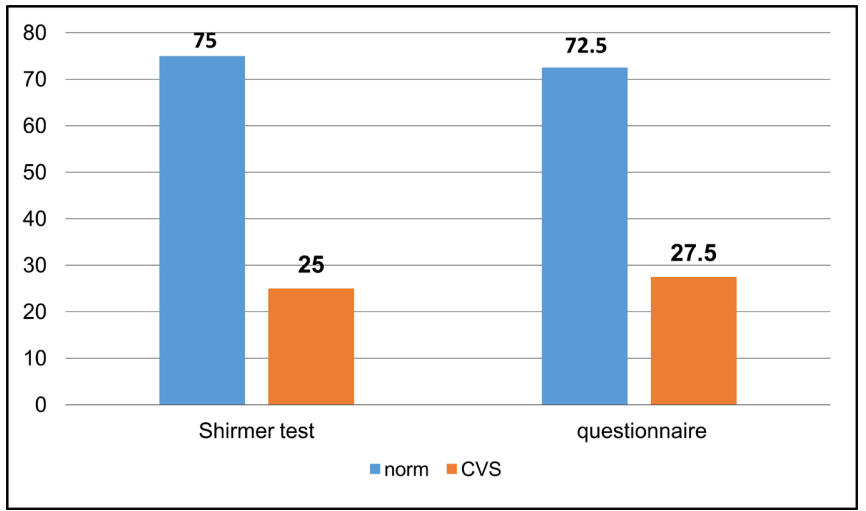

- The gender distribution shows 3 women or 33.33 $\%$ and 8 or $25.8 \%$ of men are considered to suffer CVS based on the questionnaire, and 3 or $33.33 \%$ of women and 7 or $22.6 \%$ of men on the basis of Schirmer test have dry eye symptoms (Fig. 2)

Fig. 2. Distribution of the symptoms by gender among the staff

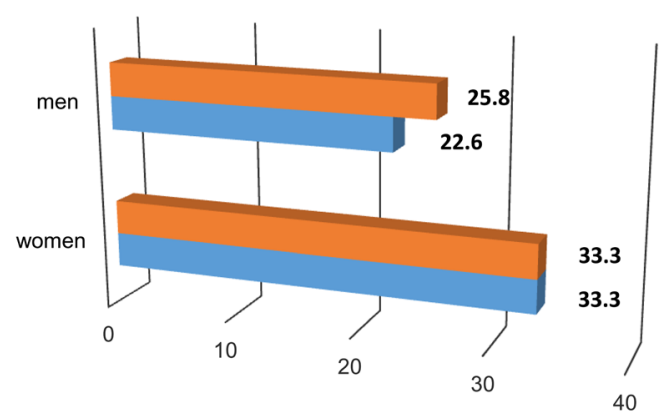

घquestionnaire $\quad$ Shirmer test

- Staff with experience more than 5 years suffer more from the symptoms of CVS than those with less than 5 years. (Fig. 3)
Fig. 3. Comparison of the results on the basis of work experience

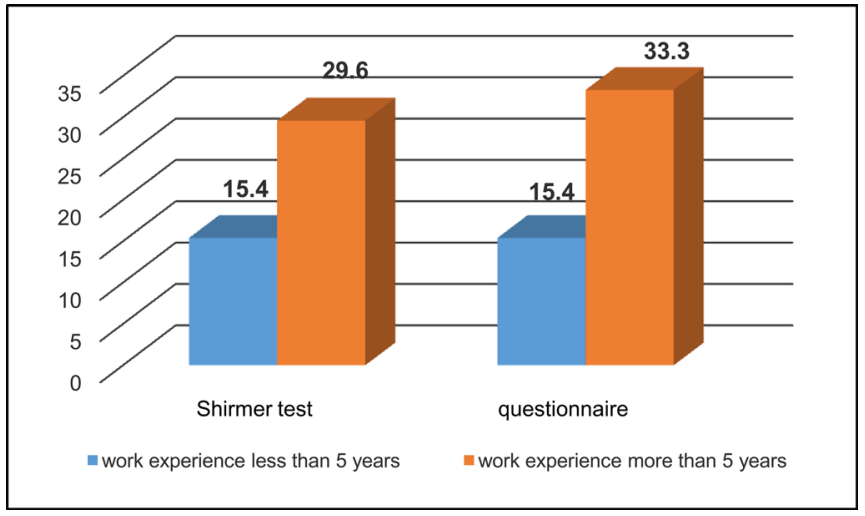

\section{DISCUSSION:}

All of the participants in the study were instructed regarding health and safety rules for work with VDT's and strictly follow them during the workday [9]. Instructions and educational seminars regarding ergonomic safety in the office also are distributed to the workers regularly. Occupational exposure to VDT's increases the risk of refraction abnormalities.

A study of the ophthalmological status of 455 workers in Bulgaria divided into 2 groups-staff with workday less than 4 hours and staff with shift more than 4 hours [10]. From those with shift more than 4 hours- $65 \%$ have refraction anomalies, and the group with half workday shift has $54 \%$ diagnosed with refraction anomalies staff members [10]. The most common refraction anomalies reported were myopia, presbyopia and hypermetropia [10]. A study reports increased blood flow to m.orbicularis oculi during computer work is a cause for eye pain [11], and increased load on m.orbicularis oculi during computer tasks is related to visual fatigue [11]. The use of progressive computer glasses has low quality evidence on the reduction of symptoms of CVS [12]. A 10-year study on video display terminal (VDT) workers reports no connection between visual fatigue and age, gender and years of work in this occupational field [5]. Relationship between visual fatigue and refractive disorders was also not proven [5]. Dry eye is a common symptom of CVS. A study on Japanese VDT workers reports 30 percent of the studied group suffers from dry eye syndrome [13]. The use of eye drops and a proper ergonomic work environment improve dry eye symptoms among computer users [14]. Due to Covid 19 pandemic and online education by children, an increase in the symptoms of CVS was discovered [15]. The tear osmolarity test is more efficient in diagnosing dry eye and has the highest sensitivity rather than other tests performed for assessment of dry eye syndrome [16]. Studies with TearLabOsmolarity System give data for the relationship between tear hyperosmolarity and dry eye syndrome [17]. 


\section{CONCLUSION:}

The results of the study predispose to further evaluation and tracking of the symptoms of CVS among this occupational group. All of the participants are aware of Ordinance No. 7 related to health and safety work conditions with video display terminals and are distributed with in- formation regarding physiological work-rest regimes. Therapy with teardrops and vitamins are distributed to the diagnosed with CVS. Occupational risk of CVS can be reduced with early diagnose, proper assessment and prevention of the symptoms.

\section{REFERENCES:}

1. Rosenfield M. Computer vision syndrome: a review of ocular causes and potential treatments. Ophthalmic Physiol Opt. 2011 Sep;31(5):502-15. [PubMed]

2. Bhanderi DJ, Choudhary S, Doshi VG. A community-based study of asthenopia in computer operators. Indian J Ophthalmol. 2008 Jan-Feb; 56(1):51-5. [PubMed]

3. Travers PH, Stanton BA. Office workers and video display terminals: physical, psychological and ergonomic factors. AAOHN J. 2002 Nov; 50(11):489-93. [PubMed]

4. Rosenfield M, Li RT, Kirsch NT. A double-blind test of blue-blocking filters on symptoms of digital eye strain. Work. 2020;65(2):343-348. [PubMed]

5. Larese Filon F, Drusian A, Ronchese F, Negro C. Video Display Operator Complaints: A 10-Year Follow-Up of Visual Fatigue and Refractive Disorders. Int J Environ Res Public Health. 2019 Jul 13;16(14):2501. [PubMed]

6. Chu C, Rosenfield M, Portello JK, Benzoni JA, Collier JD. A comparison of symptoms after viewing text on a computer screen and hardcopy. Ophthalmic Physiol Opt. 2011 Jan;31(1):

\section{9-32. [PubMed]}

7. Coles-Brennan C, Sulley A, Young G. Management of digital eye strain. Clin Exp Optom. 2019 Jan; 102(1):18-29. [PubMed]

8. Seguí Mdel M, Cabrero-García J, Crespo A, Verdú J, Ronda E. A reliable and valid questionnaire was developed to measure computer vision syndrome at the workplace. J Clin Epidemiol. 2015 Jun;68(6):662-73. [PubMed]

9. Ordinance No.7 - 15 August 2005 . Minimal requirements for ensuring health and safety labor conditions during work with video display terminals (VDT's). Bulgarian Ministry of Health. Bulgarian Ministry of labor and social politics. (in Bulgarian)

10. Dimitrova T, Zlatarova Z. Work with video display terminals and refraction abnormalities. Scripta Scientific Medica. 2009; 41(1):45-47.

11.Thorud HM, Helland M, Aarås A, Kvikstad TM, Lindberg LG, Horgen G. Eye-related pain induced by visually demanding computer work. Optom Vis Sci. 2012 Apr;89(4):E45264. [PubMed]

12. Heus P, Verbeek JH, Tikka C. Optical correction of refractive error for preventing and treating eye symptoms in computer users. Cochrane Database Syst Rev. 2018 Apr 10;4(4): CD009877. [PubMed]

13. Nakaishi H, Yamada Y. Abnormal tear dynamics and symptoms of eyestrain in operators of visual display terminals. Occup Environ Med. 1999 Jan;56(1):6-9. [PubMed]

14. Coles-Brennan C, Sulley A, Young G. Management of digital eye strain. Clin Exp Optom. 2019 Jan; 102(1):18-29. [PubMed]

15. Mohan A, Sen P, Shah C, Jain E, Jain S. Prevalence and risk factor assessment of digital eye strain among children using online e-learning during the COVID-19 pandemic: Digital eye strain among kids (DESK study-1). Indian J Ophthalmol. 2021 Jan;69(1): 140-144. [PubMed]

16. Lemp MA, Bron AJ, Baudouin C, Benítez Del Castillo JM, Geffen $\mathrm{D}$, et al. Tear osmolarity in the diagnosis and management of dry eye disease. Am J Ophthalmol. 2011 May; 151(5):792-798.e1. [PubMed]

17. Versura P, Campos EC. TearLab® Osmolarity System for diagnosing dry eye. Expert Rev Mol Diagn. 2013 Mar;13(2):119-29. [PubMed]

Please cite this article as: Nikolov PN. Computer vision syndrome: Review and methods for assessment. $J$ of IMAB. 2021 Apr-Jun;27(2):3823-3825. DOI: https://doi.org/10.5272/jimab.2021272.3823

Received: 26/11/2020; Published online: 29/06/2021

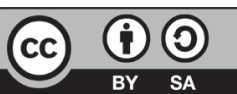

Address for correspondence:

Panayot Nikolov

Department of Hygiene and Epidemiology, Faculty of Public Health, Medical University - Varna,

55, Marin Drinov Str., 9000, Varna, Bulgaria.

E-mail: panayotnikolov04@gmail.com, 